\title{
A importância da superação de barreiras entre família e escola para a construção de um trabalho colaborativo em prol da inclusão escolar do filho e aluno com altas habilidades/superdotação
}

The importance of overcoming barriers between family and school for the construction of a collaborative work for the school inclusion of the son and student with high gifted and talented

La importancia de superar las barreras entre familia y escuela para construir un trabajo colaborativo en pro de la inclusión escolar del hijo y alumno con altas capacidades/superdotación

Andréia Jaqueline Devalle Rech

Professora doutora da Universidade Federal de Santa Maria, Santa Maria, RS, Brasil

E-mail: prof.andirech@gmail.com ORCID: https://orcid.org/0000-0001-9763-5552

Soraia Napoleão Freitas

Professora pós-doutora aposentada da Universidade Federal de Santa Maria, Santa Maria, RS, Brasil

E-mail: soraianfreitas@yahoo.com.br ORCID: https://orcid.org/0000-0003-0163-4016

Recebido em 23 de setembro de 2020

Aprovado em 09 de abril de 2021

Publicado em 27 de maio de 2021

\section{RESUMO}

A inclusão escolar dos alunos com altas habilidades/superdotação (AH/SD) tem sido um desafio para alguns professores. Esse fato resulta do desconhecimento da temática das AH/SD, decorrente, possivelmente, das concepções equivocadas difundidas socialmente, somadas a uma formação inicial incipiente no que se refere aos alunos com AH/SD. Nesse contexto, é necessário formar redes de apoio para que se efetive a inclusão escolar destes alunos. Nesse sentido, a família pode ser uma rede de apoio e tornar-se parceira da escola. Este artigo buscou compreender a articulação entre família e escola, verificando as barreiras que dificultam essa parceria e identificando possíveis influências da família no processo de inclusão escolar do filho/aluno com AH/SD. Em relação ao método, optou-se pela abordagem qualitativa do tipo estudo de caso. Os instrumentos de coleta de dados selecionados foram: "Checklist da Rotina Compartilhada e Envolvimento entre Famíliaescola", Versão para Professores e "Checklist da Rotina Compartilhada e Envolvimento entre Família-escola Versão Pais" (mãe, pai ou responsável), ambos validados por Dessen e Polonia (2011). Participaram da pesquisa 12 famílias com filhos identificados com AH/SD e 11 professoras. As considerações finais apontam para uma relação entre família e escola ainda incipiente, pois algumas barreiras foram identificadas, tendo prevalecido uma relação acusativa, o que pode estar dificultando a construção de uma relação de parceria. Foram 
http://dx.doi.org/10.5902/1984686X55329

pontuais os casos em que houve articulação entre ambas as instituições e que resultaram em maior influência/participação da família na vida escolar do filho com AH/SD.

Palavras-chave: Família; Altas habilidades/superdotação; Inclusão escolar.

\section{ABSTRACT}

The School inclusion of the gifted and talented students $(G / T)$ has been a challenge for some teachers. This fact lies on the lack of knowledge about the theme of $G / T$, which may occur due to the wrong conceptions socially widespread, adding to that an incipient initial education in relation to $\mathrm{G} / \mathrm{T}$ students. Accordingly, it is necessary to create support networks so that school inclusion of G/T students becomes effective. In this sense, the family could be a support network and set up a partnership with the school. This paper sought understand this articulation between family and school, verifying the barriers that hinder this partnership, in addition to visualizing possible influences of the family in the process of school inclusion of the child/student with the G/T. Regarding the method, the study case within the qualitative approach was chosen. The instruments of data collection selected were: Checklist of Shared Routine and Engagement between Family-school, Version for Teachers, and Checklist of Shared Routine and Engagement between Family-school, Version for Parents (mother, father, or guardian), both validated by Dessen and Polonia (2011). This study included 12 families with children identified as $\mathrm{G} / \mathrm{T}$ and 11 teachers. The final considerations point to a relation between family and school that is still incipient, due to the fact that some barriers/constraints were identified, having prevailed an accusative relationship, which may be hindering the construction of a partnership relation. There were specific cases in which there was conjunction between both institutions, and that result in greater influence/participation of the family in the school life of the G/T child.

Keywords: Family; Gifted and talented; School inclusion.

\section{RESUMEN}

La inclusión escolar de los alumnos con altas capacidades/superdotación (AH/SD) ha sido un desafío para algunos profesores. Ese hecho se debe al desconocimiento del tema de las $\mathrm{AH} / \mathrm{SD}$, consecuencia, posiblemente, de las concepciones equivocadas difundidas socialmente, sumado a una formación inicial incipiente en lo que se refiere a los alumnos con AH/SD. Por lo tanto, es necesario formar redes de apoyo para que se efectúe la inclusión escolar del alumno con AH/SD. En ese sentido, la familia puede ser una red de apoyo y volverse aliada de la escuela. Este artículo buscó comprender la articulación entre familia y escuela, verificando las barreras que dificultan esa alianza, además de identificar posibles influencias de la familia en el proceso de inclusión escolar del hijo/alumno con $\mathrm{AH} / \mathrm{SD}$. Con respecto al método, se optó por el enfoque cualitativo, de tipo estudio de caso. Los instrumentos para reunir los datos que seleccionamos fueron: Checklist de la Rutina Compartida y Relación entre Familia-Escuela, versión para profesores, y Checklist de la rutina Compartida y Relación entre Familia-Escuela, versión para tutores (madre, padre o responsable), ambos validados por Dessen y Polonia (2011). Participaron en el estudio 12 familias con hijos identificados con AH/SD y 11 profesoras. Las consideraciones finales apuntan a una relación entre familia y escuela aún incipiente, pues se identificaron algunas 
http://dx.doi.org/10.5902/1984686X55329

barreras, por lo que prevaleció una relación acusativa, lo que puede dificultar la construcción de una relación de alianza. Fueron puntuales los casos en que existió una articulación entre ambas instituciones, con mayor influencia/participación de la familia en la vida escolar del hijo con AH/SD.

Palabras clave: Familia; Altas capacidades/superdotación; Inclusión escolar.

\section{Iniciando o debate}

A inclusão escolar dos alunos público-alvo da educação especial tem recebido maior visibilidade no cenário educacional brasileiro. Um dos resultados dessa visibilidade é a disseminação de políticas públicas voltadas a garantir e viabilizar a inclusão dos alunos com altas habilidades/superdotação (AH/SD) (BRASIL, 2008, 2009, 2011, 2015).

Nesse contexto, verifica-se que as escolas têm expandido o debate no que diz respeito à inclusão dos alunos com deficiências e transtornos do espectro autista, mas poucas reconhecem os alunos com $\mathrm{AH} / \mathrm{SD}$ como sujeitos que requerem atendimento educacional especializado (AEE). Isso se dá muito embora a própria Política Nacional de Educação Especial na Perspectiva da Educação Inclusiva (BRASIL, 2008) preveja que a escola deva organizar um AEE que complemente o ensino para os alunos com deficiência e suplemente o currículo escolar de forma a potencializar as habilidades presentes nos alunos com AH/SD.

Desse modo, é notória a existência de uma lacuna entre o que prevê a política pública em questão e o que se observa nas práticas pedagógicas para os alunos com AH/SD. No entanto, é fundamental que as políticas públicas sejam propostas para a promoção da inclusão escolar, mas cabe às escolas refletirem sobre a existência de práticas excludentes, mesmo no âmbito da educação inclusiva, como, por exemplo, a invisibilidade dos alunos com AH/SD nos espaços escolares e a consequente exclusão escolar. Sendo assim, o não reconhecimento por parte da escola do aluno com AH/SD configura-se como uma das primeiras barreiras que precisam ser superadas para que esse aluno tenha seus direitos educacionais alcançados.

Outro aspecto que precisa ser destacado é a família, instituição fundamental na vida dos filhos. No caso de um filho público-alvo da educação especial, o suporte familiar faz-se ainda mais importante, devendo, portanto, ser intensificado.

No entanto, muitas famílias com filhos com AH/SD tem a confirmação da identificação da habilidade de seu filho apenas no ingresso da vida escolar deste. Embora as famílias, muitas vezes, já tenham observado comportamentos peculiares, que diferenciavam seu 
http://dx.doi.org/10.5902/1984686X55329

filho das outras crianças na mesma idade, acabavam por avaliar que esses comportamentos poderiam decorrer unicamente de estímulos providos pela própria família.

É importante destacar que as pessoas com AH/SD são aquelas que apresentam potencial superior em alguma das seguintes áreas: intelectual, liderança, psicomotricidade e artes. Tais habilidades podem se manifestar nos sujeitos de forma isolada ou combinada (BRASIL, 2008).

Renzulli (2014, p. 246, grifos do autor), teórico renomado em pesquisas a respeito das $\mathrm{AH} / \mathrm{SD}$, contribui para o debate afirmando que as pessoas desse grupo apresentam comportamentos consistentes que resultam:

[...] de uma interação entre três grupos básicos de traços humanos: habilidades gerais e/ou específicas, altos níveis de comprometimento com a tarefa e altos níveis de criatividade. Crianças que manifestam ou são capazes de desenvolver uma interação entre os três grupos requerem uma ampla variedade de oportunidades educacionais, de recursos e de encorajamento acima e além daqueles providos ordinariamente por meio de programas regulares de instrução.

O autor criou a Teoria dos Três Anéis, que se refere à interação dos três componentes mencionados: habilidade acima da média, criatividade e envolvimento com a tarefa. Para ele, as pessoas com comportamentos superdotados devem apresentar esses três componentes, os quais, porém, podem oscilar com o passar do tempo: ora um anel estará em evidência, ora outro. Contudo, os anéis nunca deixam de interagir entre si e devem apresentar consistência e intensidade na área de destaque da pessoa com AH/SD (RENZULLI, 2014).

O Ministério da Educação, no documento "Saberes e práticas da inclusão" (BRASIL, 2006, p. 22), aponta algumas características que podem ser observadas nos alunos com AH/SD:

\begin{abstract}
Alto desempenho em uma ou várias áreas; Fluência verbal e/ ou vocabulário extenso; Envolvimento ou foco de atenção direcionado a alguma atividade em especial; Desempenho elevado qualitativamente nas atividades escolares; Qualidade das relações sociais do aluno, em diversas situações; Curiosidade acentuada; Facilidade para a aprendizagem; Originalidade na resolução de problemas ou na formulação de respostas; Atitudes comportamentais de excesso para a produção ou planejamento; Habilidades específicas de destaque (áreas: artes plásticas, musicais, artes cênicas e psicomotora, de liderança, etc.) Senso de humor; Baixo limiar de frustração; Senso crítico; Defesa de suas idéias e ponto de vista; Impaciência com atividades rotineiras e repetitivas; Perfeccionismo; Dispersão ou desatenção; Resistência em seguir regras; Desenvolvimento superior atípico em relação a pessoas de igual faixa etária.
\end{abstract}


http://dx.doi.org/10.5902/1984686X55329

Cabe salientar que as características descritas são comumente observadas nas pessoas com AH/SD, mas cada sujeito é singular, provido de uma história de vida única, com seus aspectos sociais e culturais. Além disso, as características também estão em conformidade com o tipo de habilidade presente nessas pessoas e a inteligência múltipla (GARDNER, 2000) que se destaca nelas. Dito de outro modo, "apesar de várias características comuns encontradas entre indivíduos superdotados, o mais surpreendente, nesta população, é a contínua variação que ela exibe em termos de habilidades e competências [...]" (OUROFINO; GUIMARÃES, 2007, p. 43).

$O$ processo de identificação requer cautela e a participação de grande número de colaboradores, entre eles: o próprio sujeito em investigação, sua família, professores, colegas/amigos, psicólogos e professores de áreas específicas quando for o caso (música, dança, artes, etc.). A identificação pode acontecer em qualquer etapa da vida, desde a infância até a terceira idade. No entanto, certamente quanto mais cedo essa identificação for realizada, maiores serão as oportunidades de oferecer estímulos a esses sujeitos, para que seus potenciais se desenvolvam alcancem alto desempenho.

A identificação da pessoa com $\mathrm{AH} / \mathrm{SD}^{1}$ é um desafio ao profissional capacitado para tal função, pois trata-se de um processo complexo, que não deve ter como finalidade a simples identificação, mas sim o encaminhamento do sujeito para receber o atendimento educacional previsto na legislação (BRASIL, 2009), além do fato de contribuir para a construção da identidade de pessoa com AH/SD.

Logo, a identificação é importante para que a pessoa com AH/SD tenha consciência das suas habilidades, e, a partir disso, a família e a escola se articulem para promover a sua inclusão escolar. Tanto a escola quanto a família podem solicitar a avaliação do aluno/filho com comportamento de AH/SD. No entanto, como mencionado, é preciso uma avaliação global dessas habilidades, tendo em vista que os testes de inteligência, quando realizados de forma isolada, não avaliam um amplo conjunto de habilidades.

Nesse contexto, a partir do momento que a família tem confirmada a identificação de AH/SD do seu filho, inicia-se uma nova caminhada, a aceitação desse "novo" filho.

É importante pontuar que há diferentes reações familiares frente ao conhecimento de que um filho possui $A H / S D$. Algumas se preocupam, pois não gostariam que seus filhos fossem diferentes das demais crianças e adolescentes, mas, ao mesmo tempo, confortamse, pois agora compreendem determinados comportamentos observados em seus filhos, 
http://dx.doi.org/10.5902/1984686X55329

como, por exemplo, a dissincronia (TERRASIER, 2000), que pode se manifestar de forma interna e social.

A "dissincronia" interna corresponde aos ritmos heterogêneos particulares do desenvolvimento das crianças superdotadas", e a dissincronia social corresponde a "onde se expressam as dificuldades específicas no seu relacionamento com o meio ambiente" (TERRASSIER, 2000, p. 70). A dissincronia pode ser observada a partir das diferenças verificadas entre a precocidade cognitiva, em comparação com as áreas afetivas e psicomotoras, que apresentarão um desenvolvimento mediano.

Portanto, os filhos/alunos com AH/SD podem apresentar uma diferença entre os níveis cognitivos, socioafetivos e psicomotores, ou seja, poderão apresentar comportamentos emocionais de acordo com a faixa etária e, ao mesmo tempo, comportamentos cognitivos condizentes com idades superiores.

Outras famílias se sentem envaidecidas por ter um filho com AH/SD. A esse respeito, segundo Delou (2007, p. 53):

Quanto menos esclarecida for a família, mais ela fantasiará os proveitos e vantagens que poderá tirar da situação de ter um filho com altas habilidades/superdotação. Quanto mais esclarecida, mais conflitos poderá viver por não encontrar na sociedade receptividade, aceitação e atendimento apropriado às necessidades educacionais especiais de sua criança.

Para Solow (2001), quando as famílias desconhecem as concepções de AH/SD, podem enfrentar maiores dificuldades para direcionar o estímulo aos seus respectivos filhos. Já os pais que foram esclarecidos acerca dessa temática terão maiores subsídios para decidir sobre os encaminhamentos para estimular as AH/SD dos seus filhos.

Mediante tais ponderações, emerge o contexto escolar e a sua relação com a família do aluno com AH/SD, foco da discussão desse manuscrito. Como a escola e a família são importantes contextos de desenvolvimento na vida dos alunos/filhos, é relevante investigar como estas duas instituições estão se relacionando, dialogando, e se há uma busca de ações colaborativas, visando à inclusão escolar do aluno/filho com AH/SD.

Assim, o presente texto centrou o debate na relação entre família e escola, analisando a existência de possíveis barreiras entre ambas que possam dificultar e interferir na inclusão escolar do filho /aluno com AH/SD.

Espera-se, a partir desta análise, projetar estratégias que superem os entraves identificados para que a escola e a família formem uma rede de apoio ao público-alvo em 
http://dx.doi.org/10.5902/1984686X55329

questão. Com isso, almeja-se que o aluno/filho com AH/SD tenha atendidas, estimuladas e valorizadas suas habilidades, alcançado, assim, os ideais da educação inclusiva.

\section{Processos metodológicos}

Esta pesquisa caracterizou-se como qualitativa do tipo estudo de caso. A opção pela abordagem qualitativa deveu-se ao fato de esta ter como finalidade aprofundar "[...] ações e relações humanas, um lado não perceptível e não captável em equações, médias e estatísticas" (MINAYO, 2000, p. 22). A partir desse entendimento, o estudo de caso foi selecionado como método de pesquisa a fim de subsidiar a compreensão de fenômenos sociais complexos (YIN, 2010).

Participaram dessa pesquisa 12 famílias (11 mães e um pai) com filhos identificados com comportamento de AH/SD e as professoras desses alunos, todas do sexo feminino.

Em relação às professoras, foram selecionadas 11, seis delas regentes das turmas dos alunos com AH/SD que frequentavam os anos iniciais do ensino fundamental e cinco professoras conselheiras de turma, ${ }^{3}$ quando os alunos frequentavam os anos finais do ensino fundamental.

As professoras estavam lotadas em sete escolas, cinco da rede pública estadual (Escolas de 1 a 5) e duas da rede privada (Escolas 6 e 7), da cidade de Santa Maria, Rio Grande do Sul, conforme representado no Quadro 1.

Quadro 1 - Identificação das escolas e das respectivas professoras participantes

\begin{tabular}{|l|c|}
\hline \multicolumn{1}{|c|}{ ESCOLAS } & PROFESSORAS \\
\hline Escola 1 & Professora 1 \\
& Professora 2 \\
& Professora 3 \\
\hline Escola 2 & Professora 4 \\
& Professora 5 \\
\hline Escola 3 & Professora 6 \\
\hline Escola 4 & Professora 7 \\
\hline Escola 5 & Professora 8 \\
\hline Escola 6 & Professora 9 \\
\hline Escola 7 & Professora 10 \\
\hline
\end{tabular}

Fonte: Elaborado pelas autoras (2020). 
http://dx.doi.org/10.5902/1984686X55329

Com a preocupação em manter preservada a identidade dos participantes, eles serão assim nomeados: F1, referindo-se à Família 1; F2, à Família 2 e, assim, sucessivamente. Já as professoras, cuja identidade também será preservada, serão indicadas no texto como: $\mathrm{P} 1$, referindo-se à Professora 1; P2, à Professora 2 e, assim, consecutivamente.

Para coletar os dados, foram utilizadas duas versões do "Checklist da rotina compartilhada e envolvimento entre família-escola", validadas e publicadas por Dessen e Polonia (2011), isto é, a "Versão para professores" e a "Versão pais (mãe, pai ou responsável)". O primeiro instrumento possui 46 questões contendo duas opções de resposta, "sim" e "não", e foi respondido pela professora regente dos anos iniciais e pela professora conselheira dos anos finais do ensino fundamental em que estava matriculado o aluno com AH/SD cuja família participou da pesquisa.

A "Versão pais (mãe, pai ou responsável)" do "Checklist da rotina compartilhada e envolvimento entre família-escola", é composta por 55 questões, com as mesmas opções de resposta do checklist recentemente descrito. Um membro familiar respondeu ao referido instrumento.

É importante destacar que ambos os instrumentos foram aplicados de forma individual, em local e horário pré-agendados pelos participantes.

Por meio da aplicação desses dois instrumentos, foi possível verificar como tem ocorrido a relação entre família e escola, para, assim, analisar de que forma essa relação está interferindo na inclusão escolar do filho/aluno com AH/SD. Este instrumento também possibilitou uma análise das influências da família no espaço escolar, ou seja, uma análise sobre a escola oferecer e/ou oportunizar a participação da família em diferentes momentos/segmentos do cotidiano escolar ou, ainda, sobre a família mostrar-se ou não disposta a participar dessas atividades.

Os checklists foram avaliados qualitativamente de acordo com as categorias emergidas durante análise dos dados. Além disso, estes instrumentos também permitiram uma análise quantitativa, em termos de frequência, verificando quais questões foram citadas com maior ou menor frequência, a fim de compreender como cada contexto escolar e familiar interagia.

É importante mencionar que, além dos checklists, a pesquisadora também utilizou o diário de campo para registrar as falas dos participantes, pois se observou que estes, ao responderem o instrumento, comentavam a respeito de suas respostas. Assim, com a 
http://dx.doi.org/10.5902/1984686X55329

anuência dos participantes, suas falas foram gravadas e, posteriormente, transcritas, colaborando para enriquecer a análise dos dados.

Outro dado que precisa ser esclarecido diz respeito ao conhecimento dos participantes sobre a temática de AH/SD. As famílias participantes do estudo eram assíduas num projeto de extensão que ofertava enriquecimento extracurricular a alunos (seus filhos) matriculados em escolas da rede pública e privada do município de Santa Maria. Concomitantemente, essas famílias participavam de um grupo de suporte e formação na área de $\mathrm{AH} / \mathrm{SD}$, no qual eram discutidas e problematizadas características presentes nas pessoas com $\mathrm{AH} / \mathrm{SD}$, formas de identificação e atendimento educacional previsto nas políticas públicas. Sendo assim, grande parte das famílias já tinha conhecimento da temática, o que as torna mais empoderadas para atuar de forma conjunta nas escolas de seus filhos.

Em relação aos professores participantes, esse dado foi inconstante, ou seja, alguns tinham conhecimento sobre a temática de AH/SD e outros não. Observou-se que esse fator está relacionado à forma como o educador especial manejava as questões da inclusão escolar dos alunos com AH/SD junto à sua escola. Em outras palavras, quando o educador especial era atuante na área de AH/SD na sua escola, os demais professores já tinham um conhecimento prévio desse público.

Novamente, tais aspectos recaem na formação inicial ainda incipiente sobre o tema da educação especial e inclusiva, ainda mais quando o assunto diz respeito às AH/SD. Desse modo, é fundamental a proposição de cursos de formação continuada, uma vez que são uma possibilidade de discutir sobre os temas que foram fragilmente debatidos ou até inexistentes na formação inicial.

\section{Análise dos dados}

A partir da leitura atenta e minuciosa dos dois checklists, emergiram algumas categorias de análise. No presente artigo, será debatida a categoria que identificou barreiras que interferem na relação entre família e escola, repercutindo na inclusão escolar dos filhos/alunos com AH/SD. Essa categoria foi dividida em duas subcategorias, descritas na sequência: "Participação na elaboração da proposta pedagógica e do projeto políticopedagógico" e "Configuração escolar: modelos pedagógicos, estratégias pedagógicas e avaliação". 
http://dx.doi.org/10.5902/1984686X55329

\section{Categoria 1 - Barreiras que interferem na inclusão escolar do aluno com altas habilidades/superdotação}

\section{1 - Participação na elaboração da proposta pedagógica e do projeto político-pedagógico}

Esta subcategoria tem por finalidade apresentar os dados coletados junto às professoras e às famílias participantes da pesquisa, mencionando suas posições frente aos dois eixos em debate: proposta pedagógica e projeto político-pedagógico (PPP).

Em relação ao primeiro eixo, a proposta pedagógica, verificou-se, ao analisar as respostas das professoras, que a maioria delas, dez (91\%), assinalou no checklist que os pais de seus alunos são informados a respeito da proposta pedagógica da escola. Apenas a P3 (Escola 1) assinalou que isso não ocorreu com os pais de sua turma.

$$
\begin{aligned}
& \text { "Sim, nas reuniões" (Relato da P7). } \\
& \text { "Quem se interessa, sim" (Relato da P8). }
\end{aligned}
$$

Essa expressiva resposta positiva das professoras é um aspecto importante, pois indica que os familiares estariam informados acerca do funcionamento da escola como um todo: objetivos, métodos de avaliação, currículo, metodologias empregadas, entre outros. Munidos dessas informações, os pais poderão se sentir instrumentalizados, ou seja, com informações sobre o âmbito pedagógico, sendo possível que encaminhem sugestões buscando melhorias nesse aspecto.

Contudo, ao se verificar as respostas das famílias, houve uma contradição em relação ao que foi mencionado pelas professoras, pois cinco familiares (42\%) afirmaram conhecer a proposta pedagógica e sete $(58 \%)$ disseram desconhecê-la.

\footnotetext{
"Sim, que são oferecidas oficinas, do Objetivo, e que é uma escola conteudista." (Relato da F1).

"Sim. Os pais, é mostrado o calendário escolar, o que vai ser feito durante o ano." (Relato da F3).

"Sim. Todos os anos, início do ano letivo eles apresentam, regras e deveres." (Relato da F4).

"Sim, eu venho sempre quando eu recebo essa reunião de começo de ano." (Relato da F5).

"Não, só apresentam rotina. Sabemos das notas, dos valores, mas a proposta nunca foi apresentada. Seria importante, até para a gente entender, como quando foi a mudança de ano, com vários professores, com diversas matérias, seria importante a gente entender isso." (Relato da F8).
} 
http://dx.doi.org/10.5902/1984686X55329

A partir dos relatos, é possível verificar que, embora cinco familiares tenham assinalado no checklist que conheciam a proposta pedagógica da escola, muitos deles atribuíram a esse conhecimento à apresentação das regras e da rotina da escola, geralmente abordadas em uma única reunião, no início do ano letivo.

O segundo eixo analisado, o PPP refere-se à participação dos pais na construção e/ou na modificação do PPP. Nesse aspecto, sete professoras (64\%) sinalizaram "não" no checklist, ou seja, responderam que os pais de seus alunos não fizeram sugestões e/ou colaboraram na construção do PPP, e quatro professoras (36\%) marcaram que "sim".

Para Caetano e Yaegashi (2014, p. 27), "[...] a parceria com a família se constrói no projeto político-pedagógico da escola e deve ser uma iniciativa da gestão e do corpo docente". Portanto, conforme as autoras, a escola deveria ser a principal motivadora para que as famílias fossem mais participativas na construção do PPP das escolas. Logo, é possível afirmar que cabe à gestão escolar promover ações efetivas para estimular a maior participação das famílias na vida escolar de seus filhos, incluindo-se, nesse todo, as famílias dos alunos com AH/SD.

As famílias, quando inquiridas sobre o mesmo assunto, foram enfáticas em suas respostas, uma vez que $100 \%$ delas disseram não ter se envolvido na elaboração do PPP.

Algumas relataram:

\footnotetext{
"Não, porque como é uma coisa engessada, o material vem de São Paulo, vem do Objetivo." (Relato da F1).

"Não, e nunca nos apresentaram. Pra mim não, isso que o [nome do filho] estuda desde o pré ali." (Relato da F7).

"Não, nem sei o que que é isso. A única coisa que a escola faz é uma reunião no início do ano para falar as normas da escola." (Relato da F10).
}

Novamente, assim como se acredita ser fundamental a participação dos pais na vida escolar de seus filhos, seria imprenscindível o seu engajamento na construção e/ou no acompanhamento do PPP das escolas em que estudam seus filhos. Por outro lado, é preciso refletir que a escola deveria oportunizar um espaço para promover um diálogo construtivo com a família e, a partir disso, fomentar a maior interação entre ambas.

Reali e Tancredi (2005, p. 241) ampliam esse debate, pontuando que as famílias:

Dificilmente são convidadas a participar da elaboração e do desenvolvimento dos projetos pedagógicos das escolas, pois são consideradas como dispondo de poucos conhecimentos para colaborar construtivamente com esse tipo de ação escolar. 
Esse fato foi constatado na fala da F10, que expressou espanto quando foi inquirida sobre esse assunto, pois não tinha conhecimento do que se tratava o PPP. Provavelmente, muitas outras famílias desconhecem esse importante documento que deve respaldar e assegurar o desenvolvimento de práticas pedagógicas inclusivas.

Desse modo, considera-se fundamental a discussão do PPP com a comunidade escolar, pois a participação da família que tem filho com AH/SD é tão importante quanto a participação dos professores e da equipe diretiva e permitirá que a família conheça a parte pedagógica da escola e se instrumentalize para, então, poder auxiliar no processo inclusivo do filho. Em outras palavras, a escola tem assumido um discurso de que os pais deveriam ser mais participativos na vida escolar de seus filhos, mas a operacionalização dessa ação parece distante das realidades aqui pesquisadas.

Para Polonia e Dessen (2005, p. 305), "é o projeto pedagógico que permite uma flexibilização das ações conjuntas, de forma complementar, e o desenvolvimento de repertórios singulares a cada espaço educacional". Sendo assim, reitera-se que cabe à escola gerenciar, juntamente com os familiares de seus alunos, momentos de trocas e discussões pertinentes a todo o contexto escolar.

Contudo, as famílias precisam estar atentas, posto que algumas instituições escolares podem não estar preparadas para o recebimento e a implementação dessas sugestões, talvez por considerarem que os familiares de seus alunos não estão capacitados para tal, limitando sua participação ao conhecimento da dinâmica escolar, sem permitir que nela possam interferir (OLIVEIRA; MARINHO-ARAÚJO, 2010).

Nesse sentido, é fundamental que família e escola reconheçam a importância de realizarem um trabalho cooperativo, uma vez que cada uma dessas instituições tem um papel fundamental na vida do filho/aluno com $A H / S D$, exercendo papéis diferentes, mas que se complementam.

Uma instituição sempre espera algo da outra. E para que os objetivos sejam alcançados em prol do desenvolvimento e da valorização das potencialidades do aluno, é preciso que sejamos capazes de construir de modo coletivo uma relação de diálogo mútuo, em que cada parte envolvida tenha o seu momento de fala e tenha uma efetiva troca de saberes. (OLIVEIRA, 2009, p. 91).

A partir disso, acredita-se que as reuniões pedagógicas poderiam se constituir em espaços formativos para que juntas, família e escola, reflitam sobre estratégias que venham a colaborar para o processo de inclusão escolar do filho/aluno com AH/SD. 
http://dx.doi.org/10.5902/1984686X55329

Seguindo com a discussão sobre o PPP, os familiares assinalaram no checklist se haviam ou não encaminhado para a equipe escolar sugestões de mudanças, como, por exemplo, no currículo e/ou no PPP.

Dez familiares (92\%) assinalaram que não fizeram essas solicitações. Apenas a F12 informou ter encaminhado sugestões, embora essa tentativa tenha sido frustrante:

"Sim, mas nunca fui atendido... depois desisti, ele foi ficando na escola porque tinha bolsa de $50 \%$, mas já tinha vontade de tirar ele da escola há uns dois ou três anos." (Relato da F12).

O relato desse pai ilustra a angústia e o descrédito perante o sistema escolar, quando este não considera as especificidades apresentadas pelos alunos com AH/SD. A pesquisa realizada por Sakaguti (2010) vem ao encontro dessa discussão. No seu estudo, a autora afirma que:

os pais relatam a necessidade de apoio por parte do sistema escolar provendo esta mudança necessária para que seus filhos e mais crianças nas mesmas condições tenham acesso a sala de recursos e atividades de enriquecimento curricular. (SAKAGUTI, 2010, p. 95).

A F12 também expressou a necessidade de que a escola que seu filho frequentava organizasse uma proposta de enriquecimento curricular, até porque ele já participava de um projeto de extensão que proporcionava esse atendimento e a família valorizava esse trabalho e compreendia a necessidade de sua continuidade na escola.

Para Reali e Tancredi (2005, p. 241), a participação da família na escola:

[...] tem sido bastante restrita, ficando a escola como a responsável pela determinação das ações que considera necessário implementar, e que devem ser acatadas pelos pais. Esse tipo de interação revela a existência de um modelo unilateral, em que os pais muitas vezes são aceitos pela escola em termos de discurso, mas, na prática, há uma participação secundária que apenas referenda as decisões e ações da instituição.

O caso da F12 parece estar em acordo com as discussões levantadas por Reali e Tancredi (2005), uma vez que o pai relatou que acabou desistindo de procurar a equipe gestora/pedagógica, já que as demandas de seu filho com AH/SD não tinham sido consideradas. Outro fator que dificultou o processo de inclusão do aluno com AH/SD nessa escola (Escola 7 - rede privada), foi o fato de esta não contar com um professor de educação especial em seu quadro de funcionários.

Contudo, cabe pontuar que, embora apenas a presença desse profissional não fosse garantir a inclusão escolar do aluno com AH/SD, certamente, contribuiria para (re)pensar o 
http://dx.doi.org/10.5902/1984686X55329

espaço escolar, de modo a planejar e atender às necessidades educacionais apresentadas por esse aluno.

Além disso, as políticas públicas têm respaldado a oferta do AEE para os alunos com AH/SD. Nesse sentido:

A educação especial deve garantir os serviços de apoio especializado voltado a eliminar as barreiras que possam obstruir o processo de escolarização de estudantes com deficiência, transtornos globais do desenvolvimento e altas habilidades ou superdotação. ${ }^{4}$ (BRASIL, 2011, s/p).

Sabatella (2007) reafirma a importância da parceria entre família e escola. Para a autora, "o trabalho integrado com os pais, buscando o alcance dos objetivos comuns entre família e escola, é essencial para prover conhecimento adequado, valorizar e demonstrar afeição a essas crianças, aceitando suas peculiaridades” (SABATELLA, 2007, p. 148).

Entretanto, no caso em discussão, família e escola não conseguiram construir uma parceria sólida, conjunta e colaborativa. Logo, constataram-se alguns entraves entre as duas instituições. Pelo discurso da F12, a escola ficou aquém do esperado no que diz respeito à educação do seu filho com $\mathrm{AH} / \mathrm{SD}$, pois não ouviu as demandas e sugestões informadas pela família para implementar um AEE que viesse ao encontro dos interesses e dos potenciais identificados no aluno com AH/SD.

A seguir, apresentam-se alguns relatos dos familiares justificando o porquê do não encaminhamento de sugestões, como, por exemplo, em relação ao currículo e/ou ao PPP.

"Não, estou satisfeita." (Relato da F1).

"Não, por escrito não, mas já conversei e fui atendida. Um grupo de pais se reuniu e pediu mais trabalhos ao invés só de prova." (Relato da F4).

"Não. A escola é uma escola fechada." (Relato da F8).

"Não, não me arrisco, tem que entender disso para poder apontar soluções." (Relato da F11).

Conforme exposto nos fragmentos, verifica-se uma diversidade de opiniões, como é possível observar no comentário da F1, que diz estar satisfeita com a escola do seu filho, e da F4, que relata já ter sido atendida quando solicitou uma mudança na forma de avaliação. A outra família, F8, comenta que a escola é "fechada" e, por fim, o último relato, da F11, ilustra a situação de que a família não se visualiza como capaz de participar das discussões envolvendo a parte pedagógica escolar.

Portanto, quando os familiares se mostram satisfeitos com a proposta pedagógica, pois têm conseguido atender às necessidades apresentadas pelo filho com $A H / S D$, é 
http://dx.doi.org/10.5902/1984686X55329

possível compreender que a família não encaminhe sugestões para a equipe escolar. Certamente, é o caso da F1, pois seu filho, que frequenta a Escola 6 (rede privada), tem recebido o AEE no contraturno e, com isso, tem tido oportunidades de ter suas habilidades incentivadas e estimuladas. Assim, para essa família, não se identificou barreiras no diálogo com a escola de seu filho.

Essa situação difere da apresentada pela F12, que também tinha matriculado seu filho numa escola da rede privada. O aluno não tinha acesso a uma proposta de enriquecimento escolar, nem por parte do professor comum nem por parte do professor especialista (até porque a escola não dispunha desse profissional).

Sendo assim, mesmo os dois alunos com AH/SD frequentando escolas da rede privada, não havia uniformidade na proposta inclusiva destas. A respeito da relação entre escola e família, Reali e Tancredi (2005, p. 241) comentam que:

dada sua complexidade, deve ser tratada no âmbito de cada realidade específica. As escolas não são todas iguais - apesar de regidas por uma mesma legislação e apresentarem metas correspondentes - e os ambientes familiares são singulares, embora apresentem entre si semelhanças.

Desse modo, cada situação deverá ser analisada de forma particular, de modo a abstrair experiências positivas que possam ser utilizadas em outros espaços, mas sempre considerando a singularidade de cada contexto.

Contudo, é preciso um olhar atento quando os familiares afirmam não possuir conhecimentos para contribuir com a proposta pedagógica, como relatado pela F11. Nessas situações, é preciso encorajar os familiares, o que deveria ser um dos papéis da escola. Todavia, em algumas escolas:

[...] os professores têm medo de que a família termine por invadir áreas que, segundo eles, não thes pertencem, como, por exemplo: avaliação dos professores, definição de calendário e currículo escolares, entre outros. Assim, as possibilidades de participação que os professores oferecem aos pais são restritivas, ou exigem um conhecimento que os pais não possuem, acabando por afastá-los. (CAETANO; YAEGASHI, 2014, p. 25-26).

Sendo assim, é possível que seja essa a situação encontrada na escola em que a F11 tem sua filha matriculada. Talvez fosse necessário que a escola criasse diferentes oportunidades para que os pais, se assim desejassem, fossem instrumentalizados a respeito das propostas curriculares ofertadas pela escola. Dessa forma, iriam se sentir munidos de informações e, como conhecem algumas demandas específicas apresentadas pelos seus filhos com $\mathrm{AH} / \mathrm{SD}$, poderiam discutir meios que colaborassem para impulsionar os potenciais deles. 
http://dx.doi.org/10.5902/1984686X55329

\section{2 - Configuração escolar: modelos pedagógicos, estratégias pedagógicas e avaliação}

Esta subcategoria discute três grandes eixos analisados pelo ponto de vista das professoras e famílias participantes: modelos pedagógicos, estratégias pedagógicas e formas de avaliação.

\subsection{1 - Análise das respostas das professoras}

Inicialmente, será debatido a respeito das questões respondidas pelas professoras, que se referem às questões 44,45 e 46 , compiladas na sequência. A letra " $N$ " refere-se à negativa "não" e a letra "S", à afirmativa "sim". P1, P2, P3, etc. refere-se às professoras participantes.

Quadro 2 - Respostas das professoras às questões 44, 45 e 46

\begin{tabular}{|c|c|c|c|c|c|c|c|c|c|c|c|}
\hline QUESTÃO & P1 & P2 & P3 & P4 & P5 & P6 & P7 & P8 & P9 & P10 & P11 \\
\hline $\mathbf{4 4}$ & N & S & N & S & S & S & S & S & N & N & S \\
\hline $\mathbf{4 5}$ & N & N & N & S & S & N & S & N & S & N & N \\
\hline $\mathbf{4 6}$ & N & S & N & S & N & N & S & N & N & N & S \\
\hline
\end{tabular}

Fonte: Elaborado pelas autoras (2020).

Conforme observado no Quadro 2, as professoras apresentaram uma variedade de respostas. Algumas afirmaram que os pais participavam da discussão dos modelos pedagógicos (questão 44), outros participavam do conselho de classe (questão 45) e, outros discutiam questões que envolviam estratégias pedagógicas e avaliação (questão 46).

Ao analisar o quadro apresentado, nota-se que as professoras P1 e P3 (Escola 1) e P10 (Escola 6) assinalaram "não" para as três questões. De forma contrária, as professoras P4 (Escola 2) e P7 (Escola 11), afirmaram, nas três questões, que suas escolas trabalham de forma conjunta com os pais e seus filhos.

"Bom, os pais que fazem parte do conselho de classe sim, do conselho escolar, os pais e os alunos que fazem parte desse núcleo participam." (Relato da P4).

"No conselho de classe mais as séries finais que a gente faz, os pequenos a gente já não chama para os conselhos de classe, mas os finais sim." (Relato da P7). 
http://dx.doi.org/10.5902/1984686X55329

Ao analisar a questão 44, sobre modelos pedagógicos, das 11 professoras participantes da pesquisa, sete (64\%) informaram que essa proposta era implementada em suas realidades (P2, P4, P5, P6, P7, P8 e P11).

"Sim, geralmente é discutido." (Relato da P4).

Para quatro professoras (36\%), P1 e P3 (Escola 1), P9 (Escola 5) e P10 (Escola 6), os modelos pedagógicos não eram debatidos com as famílias, ou seja, essa prática não acontecia em suas escolas.

"Não, só se tem uma queixa isolada, mas é difícil ter um momento, por exemplo, vão vir os pais na escola e vamos discutir o que está acontecendo." (Relato da P10).

Em relação às questões 45 e 46, que abordaram a participação dos professores, da equipe diretiva, dos pais e de seus filhos em reuniões e/ou conselhos de classe com a finalidade de discutir questões acadêmicas, estratégias pedagógicas e formas de avaliação, observou-se respostas muito variadas e distintas da 44.

Esperava-se que as escolas que discutiram com os pais os modelos pedagógicos igualmente convidassem os pais e seus filhos para continuar o debate, dialogando também sobre as estratégias pedagógicas e as formas de avaliação. No entanto, foi constatado, após análise das três questões (44, 45 e 46), que pode haver uma barreira na relação entre família e escola, já que ambas não têm tido muitas oportunidades de estabelecer um diálogo efetivo.

Compreende-se que a escola nem sempre deseja que as famílias de seus alunos participem de reuniões que abordam os assuntos anteriormente citados, ou até mesmo se encontra despreparada para isso. Talvez a escola precise ampliar o debate acerca das questões pedagógicas, oportunizando uma maior participação dos pais e seus filhos durante esse processo. Essa era a proposição da questão 46, mas, para sete professoras (64\%), isso não acontecia em suas realidades, conforme ilustra o seguinte relato:

"Não, daí quem decide mais é a equipe dos professores." (Relato da P7).

Nesse sentido, é necessário, primeiramente, conscientizar a comunidade escolar de que a família do aluno com AH/SD pode ser uma parceira na vida escolar desse. Além disso, "considera-se que com o estreitamento dessas relações os professores podem ter maiores informações a respeito de quem são os alunos, suas famílias, sua cultura, sua vida 
http://dx.doi.org/10.5902/1984686X55329

cotidiana e isso pode ajudá-los a desenvolver o seu trabalho de forma mais competente" (REALI; TANCREDI, 2005, p. 241).

Com esse propósito, família e escola engajam-se com um objetivo em comum, ou seja, o adequado estímulo ao filho/aluno com AH/SD, para que ele possa se desenvolver de forma plena.

Assim, os papéis que cabem à família de alunos de altas habilidades/superdotação, nessa parceria, são o de demanda e o de apoio demanda de suplementação curricular para seus filhos, e apoio ao corpo docente e à administração da escola, que se propõem a fazer as adaptações necessárias. Por outro lado, cabe à escola fazer adaptações reais, que de fato promovam uma mudança no programa educacional do aluno. (GAMA, 2007, p. 64).

Diante disso, acredita-se que a criança e/ou adolescente com AH/SD será beneficiado com as trocas de experiência entre a família e a escola. Em casa, os pais devem prosseguir com o trabalho realizado pela escola, pois há algumas atividades que eles podem promover para estimular os potenciais do filho. A família também poderá contribuir com a escola ao discutir sobre os aspectos afetivos, sociais e emocionais do filho, que certamente se apresentarão como facilitadores ou dificultadores do processo inclusivo.

Oliveira e Marinho-Araújo (2010, p. 107) comungam dessa discussão e complementam:

A despeito das situações-problema que permeiam a relação família-escola, acredita-se que a iniciativa de construir uma relação harmoniosa entre as duas instituições deve ser de responsabilidade da escola e de seus profissionais, que têm uma formação específica.

Assim, considera-se mais adequado que a escola seja a responsável pela criação desses canais de comunicação com a família, uma vez que na escola se encontram os profissionais, com formação acadêmica para gerir essas reuniões.

No entanto, é preciso um olhar atento para essas questões, para que a família não se sinta desvalorizada ou minimizada perante este "saber pedagógico" apresentado pelo corpo docente. Além do mais, a família pode não ter formação específica, mas, via de regra, foi ela que sempre conviveu com o aluno, constituindo a base da sua formação pessoal. Coube aos pais oferecer aos seus filhos amor, carinho e zelo, fortalecendo-os de forma socioemocional para o enfrentamento de possíveis adversidades.

Webb (2007, p. XV, tradução nossa) aborda essa discussão quando comenta que "um lar de base sólida é especialmente importante quando as crianças superdotadas se sentem fora de lugar no mundo que as circunda". ${ }^{5}$ Nessa perspectiva, inicialmente, cabe à família 
http://dx.doi.org/10.5902/1984686X55329

promover este suporte emocional/social aos filhos com AH/SD, para que esses se compreendam e sejam munidos de recursos internos e externos para enfrentar o mundo ao seu redor.

Dessa forma, os pais poderão auxiliar a escola apresentando sugestões em relação à parte pedagógica, mas também trazendo conhecimentos sobre a vida de seus filhos com $\mathrm{AH} / \mathrm{SD}$, pois suas demandas diferem das de outras crianças. Germani e Stobäus (2006, p. 148) reforçam a necessidade de a família e a escola estabelecerem um diálogo:

Viabilizar a comunicação entre o meio familiar e escolar representou para ambos o início de um diálogo sobre a importância de traçarem objetivos convergentes no que se refere ao desenvolvimento das potencialidades da criança, das relações interpessoais com seus pares e adultos, da flexibilização afetiva e da compreensão das fases evolutivas.

Conforme o fragmento, observa-se que, na pesquisa realizada pelos autores, houve o envolvimento da família e da escola na educação do filho/aluno com AH/SD. Assim, compreende-se que ambas as instituições necessitam buscar um diálogo comum para que os objetivos traçados pela escola sejam acompanhados pela família, que poderá dar prosseguimento, enriquecendo o ambiente familiar com estímulos que vão ao encontro das habilidades identificadas no filho.

\subsection{2 - Análise das respostas dos familiares}

Quando os familiares foram inquiridos sobre se eles, os professores e a equipe da direção discutiram os modelos pedagógicos e de avaliação adotados pela escola, nove (75\%) disseram que não houve essa discussão:

\footnotetext{
"Volto a dizer, como vem engessado e eu, particularmente, como não discordo, tá tudo bem. Vem um calendário de provas com a pontuação, tudo." (Relato da F1).

"Não, até agora está tudo bem, a professora estimula eles, agora está tudo bem não sei como vai ser na sexta ou na sétima [se referindo ao sexto e sétimo anos]." (Relato da F2).
}

"Eu não entendo nada disso, dessa pontuação de provas, mudou tudo. Aí eu pergunto para meu filho." (Relato da F6).

"Não. A escola se limita muito aos professores." (Relato da F9).

"Não, eu nunca fui informada." (Relato da F11).

"Não, só falavam que era assim, nunca deram a liberdade para nós expressarmos nossa opinião." (Relato da F12). 
http://dx.doi.org/10.5902/1984686X55329

Observa-se que os pais apresentaram diferentes pontos de vista para justificar a pouca participação com a equipe escolar: alguns estavam satisfeitos com a escola, outros buscavam algumas informações junto aos próprios filhos, dois familiares relataram não ter recebido qualquer orientação sobre a proposta pedagógica e os modelos de avaliação, e a última família comentou que a própria escola definia sobre as referidas questões e não oportunizavam a participação dos pais nesse processo.

Apenas três famílias (25\%) comentaram ter tido esse envolvimento com os professores e a equipe de direção.

"Sim, no conselho escolar, onde tem um representante de cada segmento da comunidade escolar." (Relato da F3).

"Sim. A escola abre espaço." (Relato da F4).

"Sim. Nessas reuniões de início de ano." (Relato da F5).

É necessário, neste momento, retomar a mesma questão respondida pelas professoras. Quando elas foram questionadas se os pais de seus alunos participavam de reuniões pedagógicas com a equipe escolar, oito (73\%) destacaram que os pais não participavam dessas reuniões, e apenas três (27\%) disseram ter havido essa participação.

"É que tem a primeira reunião anual, mas depois eles raramente vêm, um ou outro para conversar, mas é individual, com o professor da turma e não em reuniões." (Relato da P4).

Conforme os depoimentos, é possível analisar diferentes discursos, tanto por parte dos familiares quanto dos professores. No entanto, houve um ponto de vista convergente sobre as reuniões de início de ano. Ambos, familiares e professores, acreditam que essas reuniões poderiam ser mais abrangentes, apresentando a proposta pedagógica e as formas de avaliação de modo a esclarecer aos familiares acerca desses procedimentos, estreitando essas relações e construindo um elo colaborativo e informativo que poderia se estender ao longo do ano letivo e não se resumir em apenas uma reunião inicial.

Contudo, de acordo com Polonia e Dessen (2005, p. 309), "para superar as descontinuidades entre os ambientes familiar e escolar, é necessário conhecer os tipos de envolvimento entre pais e escola e estabelecer estratégias que permitam a concretização de objetivos comuns".

Logo, como cada realidade é única, é preciso analisar cada situação, pois não há uma regra que trará benefícios para ambas as instituições. Nessa perspectiva, um dos primeiros 
passos seria a construção de um trabalho colaborativo, mas, para tanto, faz-se necessário que família e escola estejam predispostas a construí-lo.

Ao finalizar esta subunidade de análise, evidenciou-se que havia um desconhecimento, por parte das famílias participantes, da proposta pedagógica da escola. Além do mais, segundo os relatos, poucas delas tiveram a oportunidade de enviar sugestões em relação às estratégias pedagógicas e às formas de avaliação adotadas pelas escolas frequentadas pelos seus filhos. Tais aspectos se constituíram como barreiras para a construção, juntamente com a escola, de uma rede de apoio que almejasse a inclusão escolar dos filhos/alunos com AH/SD.

Do mesmo modo, os professores sinalizaram que os pais dos seus alunos foram pouco participativos no encaminhamento de propostas e sugestões para avançar no debate de estratégias que pudessem contribuir para o desenvolvimento dos potenciais presentes nos alunos com AH/SD. No entanto, também reconheceram que a escola não tem oportunizado um efetivo canal de trocas entre família e escola.

\section{Algumas reflexões finais}

O presente artigo teve o propósito de problematizar a relação entre família e escola, verificando as barreiras que dificultam a parceria entre ambas, além de buscar a identificação de possíveis influências da família no processo de inclusão escolar do filho/aluno com $\mathrm{AH} / \mathrm{SD}$.

Para atingir o objetivo proposto, esta pesquisa contou com a participação de 12 famílias com filhos identificados com AH/SD e 11 professoras, divididas entre anos iniciais e finais do ensino fundamental.

Os dados foram coletados mediante a aplicação de dois instrumentos, o "Checklist da rotina compartilhada e envolvimento entre família-escola", na "Versão para professores" e na "Versão Pais (mãe, pai ou responsável)", ambos validados por Dessen e Polonia (2011).

Após a análise da categoria "Barreiras que interferem na inclusão escolar do aluno com altas habilidades/superdotação", foram constatadas algumas dificuldades que se configuraram como barreiras entre as duas instituições. Entre elas, destaca-se uma acusação mútua entre ambas: a escola afirma que a família não participa da vida escolar do filho com AH/SD, e a família, por sua vez, assegura que a escola não é receptiva à sua participação. 
http://dx.doi.org/10.5902/1984686X55329

Por um lado, as professoras mencionaram que os familiares não participavam de forma ativa na escola, ou seja, não eram atuantes nas reuniões tampouco enviavam sugestões à escola. Por outro lado, os familiares ressaltaram que a escola restringe sua participação, impondo-Ihes limites e fronteiras, reduzindo os espaços em que essa participação é possível.

Contudo, verificou-se que as duas instituições poderiam atuar de forma mais proativa: tanto a escola poderia repensar estratégias para a família participar de forma mais ativa na vida escolar de seus filhos, quanto a família poderia se envolver em associações de pais e mestres e conselhos de classe, com a finalidade de discutir questões acadêmicas e estratégias pedagógicas visando repensar o ensino que tem sido ofertado aos filhos com AH/SD.

Outro entrave identificado diz respeito à restrita troca de experiências entre professores do ensino comum, educadores especiais e familiares. Verificou-se que faltam espaços destinados a reuniões para que sejam discutidos aspectos escolares e sociais referentes ao aluno com AH/SD.

Também foi identificado que foram poucas as ações de parceria colaborativa entre família e escola. É possível afirmar que, das 12 famílias participantes, apenas três delas, F1, F2 e F3, relataram ações como, por exemplo, atuar voluntariamente na escola do filho, participar assiduamente do conselho de pais e mestres, informar a escola sobre o parecer de identificação das AH/SD do filho, a fim de o encaminhar para participar do AEE.

Algumas famílias justificaram não ter competência para influenciar na inclusão escolar do filho com $\mathrm{AH} / \mathrm{SD}$, outras, inclusive não tinham sequer conhecimento do direito dos filhos de frequentarem um atendimento especializado, por exemplo. Outro caso foi o relatado pela F12, que não obteve êxito ao solicitar à escola que esta prestasse um atendimento adequado, que estimulasse as habilidades identificadas no filho com AH/SD.

Portanto, de forma geral, na presente pesquisa, constatou-se que a escola e a família encontram barreiras significativas em sua relação e, por conta disso, não estão obtendo sucesso em construir um trabalho colaborativo e articulado em prol da inclusão do aluno/filho com $\mathrm{AH} / \mathrm{SD}$.

Faz-se necessário, desse modo, que a escola se conscientize de que as famílias podem ser uma rede de apoio, que juntas poderão formar uma parceria, com a intenção de contribuir para a inclusão do aluno/filho com AH/SD. Nesse sentido, é necessário, primeiramente, conscientizar os profissionais da escola, minimizando suas concepções 
http://dx.doi.org/10.5902/1984686X55329

errôneas sobre esses indivíduos para, posteriormente, dialogar com essas famílias, orientando-as para que, se desejarem, atuem de forma proativa na escolarização de seus filhos com $A H / S D$.

Conclui-se que é preciso instrumentalizar tanto a família quanto a escola acerca da temática das $\mathrm{AH} / \mathrm{SD}$, buscando uma efetiva inclusão escolar dos alunos em questão. Assim sendo, a escola poderia propor uma sensibilização para que professores, educadores especiais e familiares, dentro de suas possibilidades, planejassem ações considerando as especificidades de cada realidade, unindo esforços e contribuindo cada um com seus conhecimentos, trocando experiências para repensar a proposta para um atendimento de qualidade e que respeite as individualidades dos alunos com AH/SD.

\section{Referências}

BRASIL. Ministério da Educação. Saberes e práticas da inclusão: desenvolvendo competências para o atendimento às necessidades educacionais especiais de alunos com altas habilidades/superdotação. Brasília, DF: MEC/SEESP, 2006.

\section{BRASIL. Ministério da Educação. Política Nacional de Educação Especial na}

Perspectiva da Educação Inclusiva. Brasília, DF: MEC/SEESP, 2008. Disponível em: http://portal.mec.gov.br/index.php?option=com_docman\&view=download\&alias=16690politica-nacional-de-educacao-especial-na-perspectiva-da-educacao-inclusiva05122014\&ltemid=30192. Acesso em: 30 jul. 2020.

BRASIL. Ministério da Educação. Resolução no 4, de 2 de outubro de 2009. Institui Diretrizes Operacionais para o Atendimento Educacional Especializado na Educação Básica, modalidade Educação Especial. Brasília, DF, 2009. Disponível em: http://portal.mec.gov.br/dmdocuments/rceb004_09.pdf. Acesso em: 30 jul. 2020.

BRASIL. Presidência da República. Decreto no 7.611 de 17 de novembro de 2011. Dispõe sobre a educação especial, o atendimento educacional especializado e dá outras providências. Diário Oficial da União, Brasília, DF, nov. 2011. Disponível em: http://www.planalto.gov.br/ccivil_03/_ato2011-2014/2011/decreto/d7611.htm. Acesso em: 30 jul. 2020.

BRASIL. Senado Federal. Lei, n. 113.146, de 6 de julho de 2015. Institui a Lei Brasileira de Inclusão da Pessoa com Deficiência (Estatuto da Pessoa com Deficiência). Diário Oficial da União, Brasília, DF, seção 1, p.2-11, jul. 2015. Disponível em: http://www.planalto.gov.br/ccivil_03/_ato2015-2018/2015/lei//13146.htm. Acesso em: 30 jul. 2020.

CAETANO, Luciana Maria; YAEGASHI, Solange Franci Raimundo. A relação escola e família: reflexões teóricas. In: CAETANO, Luciana Maria; YAEGASHI, Solange Franci Raimundo (Orgs.) Relação escola e família: diálogos interdisciplinares para a formação da criança. São Paulo: Paulinas, 2014. 
DELOU, Cristina Maria Carvalho. O papel da família no desenvolvimento de altas habilidades/superdotação. In: FLEITH, Denise de Souza. (org.). A construção de práticas educacionais para alunos com altas habilidades/superdotação: o aluno e a família. Brasília, DF: Ministério da Educação. 2007. V. 3. Cap. 3. p. 49-59.

DESSEN, Maria Auxiliadora; POLONIA, Ana da Costa. Checklist da rotina compartilhada e envolvimento entre família-escola: versão para pais e professores. In: WEBER, Lidia; DESSEN, Maria Auxiliadora. (Org.). Pesquisando a família: instrumentos para coleta e análise de dados. Curitiba: Juruá, 2011. p.189-194.

GAMA, Maria Clara Sodré. Parceria entre família e escola. In: FLEITH, Denise de Souza; (Org.). A construção de práticas educacionais para alunos com altas

habilidades/superdotação: o aluno e a família. Brasília, df: Ministério da Educação. 2007. V. 3. Cap. 4. p. 61-73.

GARDNER, Howard. Inteligência: um conceito reformulado. Rio de Janeiro: Objetiva, 2000.

GERMANI, Larice Maria Bonato; STOBÄUS, Claus Dieter. A intervenção centrada na família e na escola: práticas de atendimento à criança com altas habilidades/superdotação. In: FREITAS, Soraia Napoleão org.). Educação e altas habilidades/superdotação: a ousadia de rever conceitos e práticas. Santa Maria: Editora da UFSM, 2006.

MINAYO, Maria Cecilia de Souza. Ciência, técnica e arte: o desafio da pesquisa social. In: MINAYO, Maria Cecilia de Souza (org.). Pesquisa social: teoria método e criatividade. 23. ed. Petrópolis, Rio de Janeiro: Vozes, 2004. p. 9-29.

OLIVEIRA, Marilu Palma de. Expectativas da família em relação à escolarização do seu filho com altas habilidades. 2009, 128 f. Dissertação (Mestrado em Educação). Universidade Federal de Santa Maria, Santa Maria, 2009. Disponível em: http://cascavel.cpd.ufsm.br/tede/tde_arquivos/18/TDE-2010-02-09T115754Z2428/Publico/OLIVEIRA,\%20MARILU\%20PALMA\%20DE.pdf. Acesso em: 27 ago. 2020.

OLIVEIRA, Cynthia Bisinoto Evangelista de; MARINHO-ARAÚJO, Claisy Maria. A relação família-escola: intersecções e desafios. Estudos de Psicologia, Campinas, v. 27, n. 1, p. 99-108, jan./mar. 2010. Disponível em: http://www.scielo.br/pdf/estpsi/v27n1/v27n1a12.pdf. Acesso em: 04 set. 2020.

OUROFINO, Vanessa Terezinha Alves Tentes de; GUIMARÃES, Tânia Gonzaga. Características intelectuais, emocionais e sociais do aluno com altas habilidades/superdotação. In: FLEITH, Denise de Souza (org.). A construção de práticas educacionais para alunos com altas habilidades/superdotação: orientação a professores. Brasília, DF: Ministério da Educação, 2007. V. 1. Cap. 3. p. 41-51.

PÉREZ, Susana Graciela Pérez Barrera; FREITAS, Soraia Napoleão. Manual de identificação de altas habilidades/superdotação. Guarapuava: Apprehendere, 2016.

POLONIA, Ana da Costa; DESSEN, Maria Auxiliadora. Em busca de uma compreensão das relações entre família e escola. Psicologia Escolar e Educacional, v. 9 n. 2, 2005, p. 303-312. Disponível em: http://www.scielo.br/pdf/pee/v9n2/v9n2a12.pdf. Acesso em: 30 ago. 2020. 
REALI, Aline Maria de Medeiros Rodrigues; TANCREDI, Regina Maria Simões Puccinelli. A importância do que se aprende na escola: a parceria escola-famílias em perspectiva.

Paidéia, v. 15, n. 31, p. 239-247, 2005. Disponível em:

http://www.scielo.br/pdf/paideia/v15n31/11.pdf. Acesso em: 27 ago. 2020.

RENZULLI, Joseph. A concepção de superdotação no modelo dos três anéis: um modelo de desenvolvimento para a promoção da produtividade criativa. In: VIRGOLIM, Angela Magda Rodrigues; KONKIEWITZ, Elisabete Castelon. (org.). Altas

habilidades/superdotação, inteligência e criatividade: uma visão multidisciplinar. Campinas, São Paulo: Papirus, 2014. Cap. 9. p. 219-264.

SABATELLA, Maria Lúcia Prado. Atendimento às famílias de alunos com altas habilidades. In: FLEITH, Denise de Souza; ALENCAR, Eunice Maria Lima Soriano de (org.). Desenvolvimento de talentos e altas habilidades: orientação a pais e professores. Porto Alegre: Artmed, 2007. Cap.11. p. 143-150.

SAKAGUTI, Paula Mitsuyo Yamasak. Concepções de pais sobre as altas habilidades/superdotação dos filhos inseridos em atendimento educacional especializado. 2010, 130 f. Dissertação (Mestrado em Educação) - Universidade Federal do Paraná, Curitiba, 2010. Disponível em:

http://dspace.c3sl.ufpr.br:8080/dspace/bitstream/handle/1884/24890/DISSERTACAO_PA ULA_SAKAGUTI.pdf?sequence=1\&isAllowed=y. Acesso em: 27 ago. 2020.

SOLOW, Razel. Parents conception of giftedness. Gifted child today. 2001. V. 4. Disponível em:

http://www.casenex.com/casenet/pages/readings/specialPops/lookingForGiftedness/paren tConcept.htm. Acesso em: 10 set. 2020.

TERRASSIER, Jean Charles. La disincronía de los niños precoces. In: MATE, Yolanda Benito (coord.). Problemática del niño superdotado. 3. ed. Salamanca: Amarú Eidcionaes, 2000. p. 69-74.

WEBB, James. The importance of parentes. In: WEBB, James; GORE, Janet.; AMEND, Edward; DEVRIES, Arlene. (org.). Guiding the social and emotional development of gifted youth: a practical guide for educators and counselors. Arizona: Great Potential Press, Inc. 2007. Disponível em:

https://books.google.com.br/books?id=ZyVXGPPj9rgC\&printsec=frontcover\&hl=pt-

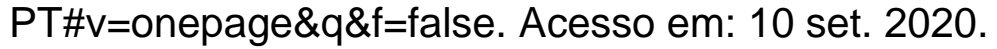

YIN, Robert. Estudo de caso: planejamento e métodos. Tradução de Ana Thorell. 4. ed. Porto Alegre: Bookman, 2010.

\section{Notas}

${ }^{1} \mathrm{O}$ foco desse artigo não centrou o debate no processo de identificação, assim quem desejar ampliar as leituras nesse campo poderá consultar Pérez e Freitas (2016).

2 Texto original: "La disincronía interna concierne a los particulares ritmos heterogéneos del desarrollo de los niños superdotados y la disincronía social donde se expresan las dificuldades específicas en su relación con su entorno". 
${ }^{3}$ Como os anos finais do ensino fundamental são compostos por vários professores, nesta pesquisa foram selecionadas para participar as professoras conselheiras, eleitas pelos alunos para representá-los. Tendo isso em vista, acredita-se que este professor é o profissional que tem maior contato com os alunos na resolução de problemas, bem como maior proximidade/atenção dispensada às famílias que têm filhos nessa etapa escolar.

${ }^{4}$ Embora esse decreto utilize a terminologia "altas habilidades ou superdotação", o documento referência que instituiu a educação inclusiva no Brasil deverá continuar sendo a Política Nacional de Educação Especial na Perspectiva da Educação Inclusiva (BRASIL, 2008). Portanto, o termo adotado nesse manuscrito será o de "altas habilidades/superdotação". (Conselho Brasileiro para Superdotação. Disponível em: http://conbrasd.org/wp/.

${ }^{5}$ Texto original: "a solid home foundation is especially important when gifted children feel out of place with the surrounding world" (WEBB, 2007, p. XV).

(c) (i) (9) International (CC BY-NC 4.0) 